\title{
Dampness and mould in schools and respiratory symptoms in children: the HITEA study
}

\author{
Alicia Borràs-Santos, ${ }^{1,2,3,4}$ José $\mathrm{H}$ Jacobs, ${ }^{5}$ Martin Täubel, ${ }^{6}$ \\ Ulla Haverinen-Shaughnessy, ${ }^{6}$ Esmeralda JM Krop, ${ }^{5}$ Kati Huttunen, ${ }^{7}$ \\ Maija-Riitta Hirvonen, ${ }^{6,7}$ Juha Pekkanen, ${ }^{6}$ Dick JJ Heederik, ${ }^{5}$ Jan-Paul Zock, ${ }^{1,2,3}$ \\ Anne Hyvärinen ${ }^{6}$
}

\begin{abstract}
- Additional material is published online only. To view please visit the journal online (http://dx.doi.org/10.1136/ oemed-2012-101286).

${ }^{1}$ Centre for Research in Environmental Epidemiology (CREAL), Barcelona, Spain ${ }^{2}$ Hospital del Mar Medical Research Institute (IMIM), Barcelona, Spain

${ }^{3}$ CIBER Epidemiología y Salud Pública (CIBERESP), Barcelona Spain

${ }^{4}$ Department of Experimental and Health Sciences, Universitat Pompeu Fabra (UPF), Barcelona, Spain ${ }^{5}$ Division of Environmental Epidemiology, Institute for Risk Assessment Sciences (IRAS), Utrecht University, Utrecht, The Netherlands

${ }^{6}$ Department of Environmental Health, National Institute for Health and Welfare, Kuopio, Finland

${ }^{7}$ Department of Environmental Science, University of Eastern Finland, Kuopio, Finland
\end{abstract}

Correspondence to Dr Alícia Borràs Santos, Centre for Research in Environmental Epidemiology (CREAL), Barcelona Biomedical Research Park (PRBB), 88, E-08003 Barcelona, Spain; aborras@creal.cat

Received 19 November 2012 Revised 19 May 2013 Accepted 27 May 2013 Published Online First 17 June 2013

\section{SLinked}

- http://dx.doi.org/10.1136/ oemed-2013-101641

To cite: Borràs-Santos $A$, Jacobs JH, Täubel $M$, et al. Occup Environ Med 2013;70:681-687.

\section{ABSTRACT}

Background The adverse respiratory health effects of dampness and mould in the home have been extensively reported, but few studies have evaluated the health effects of such exposures in schools.

Objectives To assess the associations between dampness and mould in school buildings and respiratory symptoms among 6-12-year-old pupils in three European countries with different climates.

Methods Based on information from self-reports and observations, we selected 29 primary schools with and 27 without moisture damage in Spain, the Netherlands and Finland. Information on respiratory symptoms and potential determinants was obtained using a parentadministered questionnaire among 6-12-year-old pupils. Country-specific associations between moisture damage and respiratory symptoms were evaluated using multivariable multilevel mixed effects logistic regression analysis.

Results Data from 9271 children were obtained. Nocturnal dry cough was consistently associated with moisture damage at school in each of the three countries: OR 1.15; $95 \% \mathrm{Cl} 1.00$ to 1.30 with p for heterogeneity 0.54 . Finnish children attending a moisture damaged school more often had wheeze (OR 1.36; CI 1.04 to 1.78), nasal symptoms (OR 1.34; $\mathrm{Cl} 1.05$ to 1.71) and respiratory-related school absence (OR 1.50; $\mathrm{Cl} 1.10$ to 2.03). No associations with these symptoms were found in the Netherlands or Spain ( $p$ for heterogeneity $<0.05$ ).

Conclusions Moisture damage in schools may have adverse respiratory health effects in pupils. Finnish school children seem to be at higher risk, possibly due to quantitative and/or qualitative differences in exposure.

\section{INTRODUCTION}

People generally spend between $80 \%$ and $90 \%$ of their time indoors depending on climate, season, age, sex, occupation and health status and so indoor air quality is a potential public health issue. Indoor air problems can be due to dampness in buildings. Dampness is defined by the WHO as 'any visible, measurable or perceived outcome of excess moisture that causes problems in buildings, such as mould, leaks or material degradation, mould odour or directly measured excess moisture (in terms of relative humidity or moisture content) or microbial growth'. According to the WHO, the National Academy of Sciences (USA) and the

\section{What this paper adds}

- Exposure to dampness and mould in the home has been associated with adverse respiratory health effects.

- Dampness and mould in schools may also have adverse respiratory health effects in children, particularly in Northern Europe.

- Geographical differences in these effects may be related to qualitative and/or quantitative microbial exposure differences due to variations in climate and in building characteristics.

- Avoidance or remediation of damp and mould problems in school buildings may benefit pupils' respiratory health.

Institute of Medicine (USA), the prevalence of home dampness varies from $10 \%$ to $50 \%$ in affluent countries and is similar in developing countries. ${ }^{1}{ }^{2}$ A recent European review has shown a prevalence of home dampness of $12 \%$. $^{3}$

Several epidemiological studies conducted among adults and children have found an association between indicators of indoor dampness and health outcomes such as respiratory symptoms, respiratory infections and exacerbation of asthma. ${ }^{1}$ 4-7 Dampness and moisture in buildings can lead to microbial growth and harmful emissions into indoor air, but the causal mechanisms and aetiological agents are still largely unknown. 589

Children are considered more susceptible to indoor air pollutants because their lungs and immune system are still developing. The majority of epidemiological studies on the respiratory effects of indoor dampness among school-aged children have been conducted in dwellings. ${ }^{6} \quad 7 \quad 10 \quad 11$ However, children spend a large portion of their time at school, so it is important to study the health effects of dampness in school buildings. The health effects associated with dampness exposures in schools are likely to be similar to those observed for damp houses, but relevant evidence is limited. ${ }^{17-9} 12$ The majority of studies carried out in schools were conducted in Scandinavian countries $^{8} 13$ and were based on limited numbers of schools. ${ }^{12}{ }^{14-17}$ A study in Asia showed associations between respiratory symptoms and observed mould 
growth in schools. ${ }^{18}$ Other Asian school studies observed associations between microbial markers in dust and respiratory symptoms. ${ }^{19-20}$ Only one recent European study assessed the effects of indoor air quality in schools on the respiratory health of children living in several European countries. ${ }^{21}$ This study showed an association between viable moulds and fungal DNA levels in classrooms and respiratory symptoms, including decrease in lung function. No country-specific results were given.

From 2008 onwards, the health effects of dampness and exposure to indoor microbial and other contaminants have been investigated in schools and dwellings in the study 'Health Effects of Indoor Pollutants: Integrating Microbial, Toxicological and Epidemiological Approaches (HITEA)'. In the first phases of the HITEA project during 2008, a cross-sectional school-based study was conducted in three European countries (Spain, the Netherlands and Finland) and covered more than 50 school buildings.

The aim of the present study was to assess the association between dampness and mould in school buildings and respiratory symptoms among 6-12-year-old pupils in three European regions with different climates. The study used semi-quantitative methods that have shown more consistent associations between dampness problems and health outcomes than quantitative estimates. ${ }^{7}$ In addition, we explored the effects of dampness at school among pupils with and without self-reported dampness at home because the additional effects of dampness in school may not be detected if the prevalence of dampness in the homes of the children is high or if dampness in the two microenvironments is correlated.

\section{METHODS}

\section{Study design}

In Spain, all elementary schools in five districts $(\mathrm{N}=439)$ were approached. In the Netherlands, a random sample of a total of 263 schools were invited to participate $(60 \%$ of all schools in the province of Utrecht). In Finland, large elementary schools $(\mathrm{N}=59)$ near the study centre in Kuopio were targeted. The study flowchart is shown in online supplementary figure 1. Information about the condition of school buildings was collected for primary schools in Spain $(\mathrm{N}=85)$, the Netherlands $(\mathrm{N}=92)$ and Finland $(\mathrm{N}=59)$ using an internet-based questionnaire addressed to the school principals. The correlation between dampness reported in the principals' questionnaires and that identified in inspection visits was relatively high. ${ }^{22} \mathrm{We}$ obtained information on current and past dampness problems including condensation on windows and other cold surfaces, and on water or moisture damage such as plumbing leaks and roof leaks. In addition, we asked about visible mould growth on building surfaces or structures inside the building. In each country, at least 20 schools that fulfilled the criteria were selected, half of them with and half of them without reported dampness, moisture damage and/or visible mould. The chosen schools were a convenient distance from the centres conducting the study. In each country, school buildings were inspected by centrally trained field workers following a common protocol and using standardised checklists and surface moisture recorders. Visual observation data were collected on building characteristics, moisture damage and other potential determinants of poor indoor air quality and used to categorise schools as damaged or non-damaged. Exposure was addressed at the school level. We considered all pupils from a damaged school as exposed and all pupils from a non-damaged school as nonexposed. From among these schools, at least eight damaged and eight non-damaged schools per country were selected, based on the number of damage sites in the classrooms and their extent and observed severity during the inspectors' visits, as described recently. ${ }^{22}$ Health questionnaires were then distributed to pupils in all 29 damaged and 28 non-damaged schools selected. Three 'heterogeneous' schools consisted of one building that was classified as damaged and another that was classified as non-damaged.

Degree of exposure was defined based on different concepts using data from the standardised inspection checklists. Severe damage in the classroom was based on a severity score of 3, 4 or 5. A large area of damage in the classrooms was defined as being more than $5 \mathrm{~m}^{2}$ of classroom moisture damage. Finally, the observed presence or absence of visible mould in at least one classroom in the school was taken into account.

\section{Assessment of the respiratory health status of the pupils}

Information was collected through a parent-administered questionnaire. We aimed to recruit all primary school children aged from 6 to 12 years. The respiratory health status of the children was assessed using questions from the validated International Study of Asthma and Allergies in Childhood questionnaire ${ }^{23}$ translated into the different languages. The current and past respiratory symptoms considered in the analyses are described in online supplementary table 1 . The 1 -year period prevalence of respiratory infections, apart from colds, defined as reported influenza, tonsillitis, otitis media, sinusitis, bronchitis and/or pneumonia in the last year was determined with the question: 'How many times in the last 12 months, has your child had any of the following infections?' followed by a list of seven respiratory infections (common cold, influenza, tonsillitis, otitis, sinusitis, bronchitis and pneumonia).

Absence from school due to respiratory problems was determined with the question: 'In the last 12 months, how many days (or part days) of school has your child missed because of wheezing or asthma?'.

Additional information was collected on sex, age, weight and height, parental allergies, socioeconomic status, early life exposures and conditions, residential history and physical activity. An affirmative answer to questions on water damage, wet or damp spots on surfaces, mould on surfaces and/or a mouldy odour in the pupil's house was considered to indicate dampness or mould problems in the home in the last year. The study was approved by the ethics committees of each study centre.

\section{Data analysis}

Statistical analyses were performed using STATA V.10.1. An initial descriptive analysis was carried out where we assessed the differences in characteristics between pupils from damaged and non-damaged schools with a $\chi^{2}$ test. Associations between dampness problems in the school and other factors that could potentially confound the association with health outcomes were assessed for each of the three countries by simple logistic regression analysis obtaining the crude OR with the 95\% CI.

We selected potential confounders based on previous evidence (sex, age and moisture damage at home) and other confounders based on associations with both health outcome and exposure (such as educational level). Adjusted country-specific analyses for associations between moisture damage in the school and respiratory health outcomes were performed using multilevel mixed effects logistic regression analyses adjusted for sex, age, educational level, moisture damage in the home and school as group variable to adjust for possible correlation between children within one school. 
Table 1 Characteristics of the study population by country and exposure to dampness/moisture damage at school

\begin{tabular}{|c|c|c|c|c|c|c|}
\hline \multirow[b]{2}{*}{ School exposure } & \multicolumn{2}{|l|}{ Spain } & \multicolumn{2}{|c|}{ The Netherlands } & \multicolumn{2}{|l|}{ Finland } \\
\hline & $\begin{array}{l}\text { Damaged } \\
(n=1425)\end{array}$ & $\begin{array}{l}\text { Non-damaged } \\
(n=1333)\end{array}$ & $\begin{array}{l}\text { Damaged } \\
(n=1146)\end{array}$ & $\begin{array}{l}\text { Non-damaged } \\
(n=1305)\end{array}$ & $\begin{array}{l}\text { Damaged } \\
(n=1903)\end{array}$ & $\begin{array}{l}\text { Non-damaged } \\
(n=2159)\end{array}$ \\
\hline Girls & $678(48 \%)$ & $659(49 \%)$ & $593(52 \%)$ & $685(52 \%)$ & $1006(53 \%)$ & $1098(51 \%)$ \\
\hline Age (mean (SD) in years) & $9.1(1.8)$ & $8.8(1.7)$ & $9.2(1.8)$ & $8.9(1.8)$ & $10.0(1.8)$ & $10.0(1.9)$ \\
\hline BMI (mean (SD) in $\left.\mathrm{kg} / \mathrm{m}^{2}\right) \dagger$ & $17.9(3.0)$ & $17.5(3.0)$ & $16.5(2.4)$ & $16.4(2.5)$ & $17.5(3.0)$ & $17.6(2.9)$ \\
\hline Both parents from another country & $217(15 \%)$ & $132(10 \%)^{*}$ & $57(5 \%)$ & $192(15 \%)^{*}$ & $20(1 \%)$ & $24(1 \%)$ \\
\hline Low parental educational level & $673(49 \%)$ & $570(44 \%)^{*}$ & $440(40 \%)$ & $512(42 \%)$ & $986(53 \%)$ & $1007(48 \%)^{*}$ \\
\hline Parental history of asthma & $232(18 \%)$ & $208(17 \%)$ & $246(22 \%)$ & $271(21 \%)$ & $327(18 \%)$ & $356(17 \%)$ \\
\hline Parental history of nasal allergiest & $488(37 \%)$ & $505(41 \%)^{*}$ & $625(55 \%)$ & $667(52 \%)$ & $1156(64 \%)$ & $1335(65 \%)$ \\
\hline Parental history of skin allergiest & $588(44 \%)$ & $612(49 \%)^{*}$ & $550(49 \%)$ & $622(48 \%)$ & $1006(56 \%)$ & $1163(57 \%)$ \\
\hline Moisture damage in the home & $267(19 \%)$ & $261(20 \%)$ & $292(25 \%)$ & $303(23 \%)$ & $156(8 \%)$ & $171(8 \%)$ \\
\hline Passive smoking in the home & $424(30 \%)$ & $346(26 \%)^{*}$ & $165(15 \%)$ & $163(13 \%)$ & $5(0.3 \%)$ & $3(0.1 \%)$ \\
\hline Older siblings & $612(43 \%)$ & $620(47 \%)$ & $602(53 \%)$ & $666(51 \%)$ & $1141(60 \%)$ & $1279(59 \%)$ \\
\hline Current pet keeping & $542(39 \%)$ & $451(35 \%)^{*}$ & $613(54 \%)$ & $570(44 \%)^{*}$ & $917(49 \%)$ & $849(40 \%)^{*}$ \\
\hline Physical activity§ & $810(60 \%)$ & $809(64 \%)^{*}$ & $762(69 \%)$ & $878(70 \%)$ & $1642(86 \%)$ & $1852(87 \%)$ \\
\hline
\end{tabular}

Number (\%) are given, unless otherwise specified.

tMore than $5 \%$ missing $(5-10 \%)$.

$\ddagger$ Water damage and/or wet or damp spots on surfaces and/or mould on surfaces and/or mouldy odour at home in the last 12 months.

$\S$ Exercise outside school hours more than once a week.

${ }^{*} p<0.05$ for difference between pupils from damaged and non-damaged schools ( $\chi^{2}$ test).

$\mathrm{BMI}$, body mass index.

For all analyses, country-specific estimates were combined and potential heterogeneity between countries was examined by using standardised methods for random effects meta-analysis. ${ }^{24}$

\section{RESULTS}

The overall response rate for the health survey was $62 \%$, with 9271 questionnaires collected from over 15129 eligible children. The response rate was higher in Finland (72\%) than in Spain (54\%) and the Netherlands (59\%). In the latter two countries, the response rates were higher in the non-damaged schools compared to the damaged schools (see online supplementary table 2).

Children born to foreign parents were more common in Spanish and Dutch schools than in Finnish schools (table 1). In Spain, the proportion of such children was significantly higher in damaged schools than in non-damaged schools, while it was lower in the Netherlands. In Spain and Finland, more children with less educated parents attended a damaged school. Passive smoking at home was more common in Spain compared to the other two countries, and higher in children attending damaged schools. Having animals at home was more common in children attending a damaged school in all three countries. Children with higher levels of exercise were more likely to attend non-damaged schools in Spain (table 1 and online supplementary table 3 ).

Asthma prevalence was lower in Spain compared to the Netherlands and Finland (table 2). The prevalence of hay fever was also lower in Spain than in Finland, while nasal symptoms in the last 12 months showed a similar prevalence in Spain and the Netherlands but a higher prevalence in Finland. For Spain and

Table 2 Health outcomes of the study population by country and exposure to dampness/moisture damage at school

\begin{tabular}{|c|c|c|c|c|c|c|}
\hline & \multicolumn{2}{|l|}{ Spain } & \multicolumn{2}{|c|}{ The Netherlands } & \multicolumn{2}{|l|}{ Finland } \\
\hline & $\begin{array}{l}\text { Damaged } \\
(n=1425)\end{array}$ & $\begin{array}{l}\text { Non-damaged } \\
(n=1333)\end{array}$ & $\begin{array}{l}\text { Damaged } \\
(n=1146)\end{array}$ & $\begin{array}{l}\text { Non-damaged } \\
(n=1305)\end{array}$ & $\begin{array}{l}\text { Damaged } \\
(n=1903)\end{array}$ & $\begin{array}{l}\text { Non-damaged } \\
(n=2159)\end{array}$ \\
\hline Ever asthma & $94(7 \%)$ & $67(5 \%)$ & $134(12 \%)$ & $133(10 \%)$ & $189(10 \%)$ & $204(10 \%)$ \\
\hline Ever hay fever & $126(9 \%)$ & $127(10 \%)$ & NA & NA & $539(29 \%)$ & $594(28 \%)$ \\
\hline \multicolumn{7}{|l|}{ Symptoms in the last 12 months } \\
\hline Wheezing & $143(10 \%)$ & $145(11 \%)$ & $110(10 \%)$ & $125(10 \%)$ & $281(15 \%)$ & $239(11 \%)^{*}$ \\
\hline Asthma attack & $34(2 \%)$ & $28(2 \%)$ & $44(4 \%)$ & $39(3 \%)$ & $67(4 \%)$ & $77(4 \%)$ \\
\hline Nasal symptoms & $330(24 \%)$ & $313(24 \%)$ & $267(24 \%)$ & $304(24 \%)$ & $707(39 \%)$ & $649(31 \%)^{*}$ \\
\hline Congestion/phlegm & $99(7 \%)$ & $90(7 \%)$ & $103(9 \%)$ & $119(9 \%)$ & $222(12 \%)$ & $202(9 \%)^{*}$ \\
\hline Dry cough at night & $296(22 \%)$ & $250(20 \%)$ & $226(20 \%)$ & $252(20 \%)$ & $317(17 \%)$ & $277(13 \%)^{*}$ \\
\hline Any infectiont & $744(62 \%)$ & $715(63 \%)$ & $656(61 \%)$ & $731(60 \%)$ & $783(44 \%)$ & $852(42 \%)$ \\
\hline Respiratory medication & $165(12 \%)$ & $165(13 \%)$ & $109(10 \%)$ & $124(10 \%)$ & $226(12 \%)$ & $222(10 \%)$ \\
\hline $\begin{array}{l}\text { Missed school days caused by } \\
\text { respiratory problems }\end{array}$ & $122(9 \%)$ & $127(10 \%)$ & $58(5 \%)$ & $55(4 \%)$ & $103(5 \%)$ & $80(4 \%)^{*}$ \\
\hline
\end{tabular}


the Netherlands, the prevalence rates for respiratory symptoms were essentially identical for children from damaged and nondamaged schools, whereas the Finnish children in damaged schools reported these symptoms in the past year more frequently than children in non-damaged schools. This was true for most symptoms under study. These associations reached statistical significance for Finnish schoolchildren for wheezing, nasal symptoms, congestion and phlegm without a cold, dry cough at night and school absence due to respiratory problems (table 2). A similar tendency was also seen after adjustment for different confounders including sex, age, parental educational level and moisture damage at home (figure 1). When the associations between moisture damage in the school building and the prevalence of selected respiratory symptoms in the last 12 months were studied, crude ORs were higher and more often significant than country-combined adjusted ORs, but all pointed in the same direction. Further adjustment for passive smoking at home, parental allergies and body mass index did not change ORs. Attending a damaged school was associated with having more respiratory symptoms, but this was only statistically significant for dry cough at night (OR 1.15 ; 95\% CI 1.00 to 1.33 ) in all the countries without indications of heterogeneity (figure 1). Analyses per country showed that significant associations in the Finnish pupils for wheezing in the last 12 months (OR 1.36; 95\% CI 1.04 to 1.78 ) were different than in the other two countries ( $\mathrm{p}$ for heterogeneity 0.049 ). For nasal symptoms in the last year, an OR of 1.34 (95\% CI 1.06 to 1.71) was found for Finland and again significant heterogeneity between countries was seen $(p=0.05)$. Finally, for absence from school related to respiratory problems in the last 12 months, we observed an OR of 1.50 (95\% CI 1.10 to 2.03 ) for Finland, with significant heterogeneity between countries $(p=0.03)$ (figure 1$)$.

When visible mould was used as an additional criterion to further subgroup school buildings into non-damaged/no visible mould, damaged/no visible mould and damaged/visible mould categories, a clear dose-response relationship was observed for sickness absence in Finland and asthma medication in the last 12 months (table 3). This tendency for a dose-response relationship was seen for all outcomes, although the trend did not always reach statistical significance. A dose -response relationship was

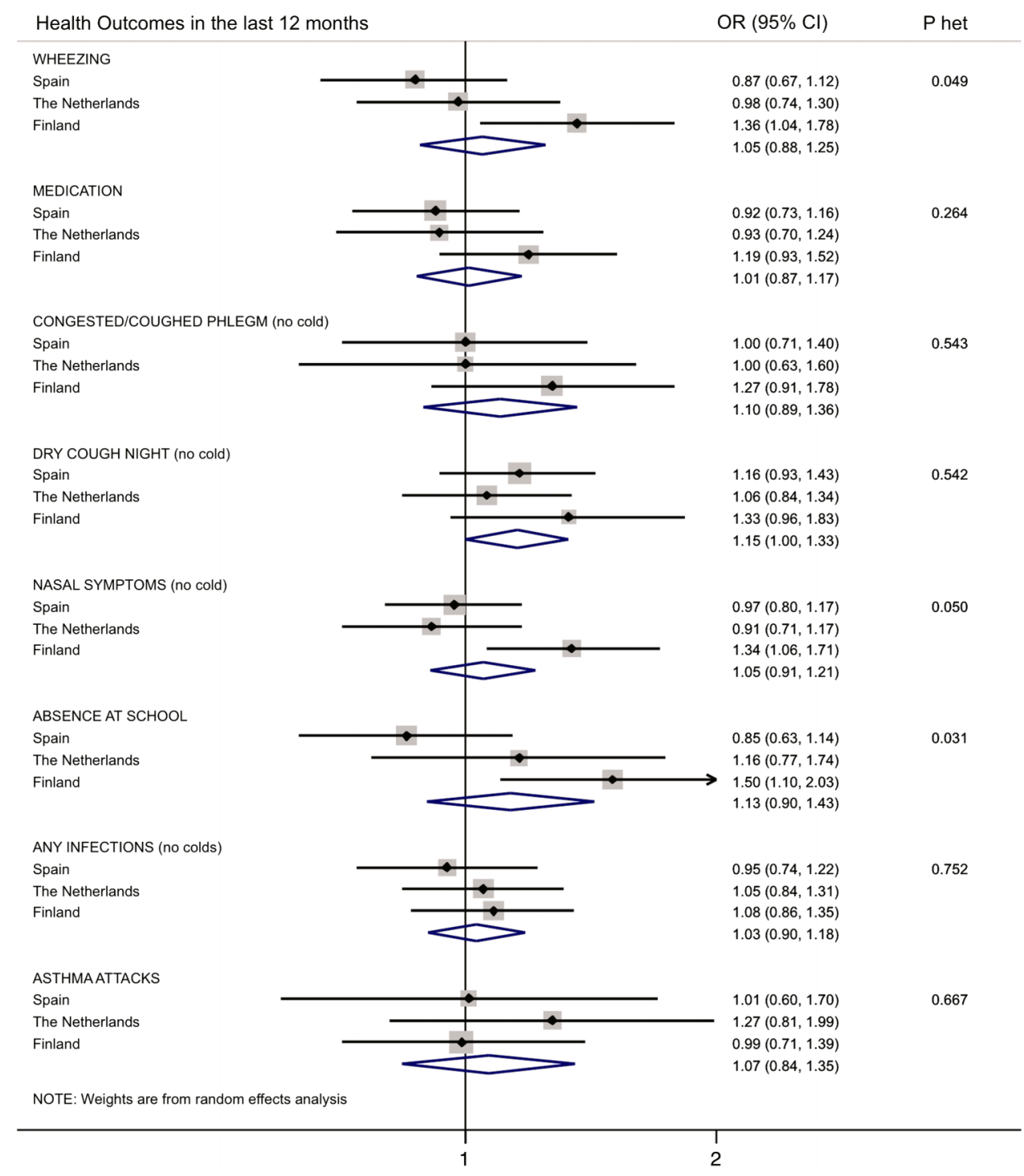

Figure 1 Adjusted associations between moisture damage in the school building and the prevalence of selected respiratory symptoms in the last 12 months (combined meta-analysis). Odds Ratios by country ( $95 \%$ Confidence Intervals) adjusted for sex, age, parental educational level, moisture damage at home and school (group variable). The diamond indicates $95 \% \mathrm{Cl}$ of the combined risk estimate from the model, with country as the random effect. $P$ het: test for heterogeneity between countries. Access the article online to view this figure in colour. 
Table 3 Associations between exposure to moisture damage and visible mould in primary school buildings and respiratory symptoms in Finnish pupils $(n=4062)$

\begin{tabular}{|c|c|c|c|c|}
\hline & Non-damaged, no visible mould & Damaged, no visible mould & Damaged, visible mould & $p$ Value for linear trend \\
\hline Number of schools & 8 & 7 & 2 & \\
\hline Number of pupils & 2159 & 1612 & 291 & \\
\hline Wheezing last 12 months & 1 (referent) & $1.36(1.03$ to 1.80$)$ & $1.37(0.86$ to 2.19$)$ & 0.047 \\
\hline Asthma medication last 12 months & 1 (referent) & $1.11(0.87$ to 1.42$)$ & $1.63(1.09$ to 2.42$)$ & 0.035 \\
\hline Congestion or phlegm last 12 months & 1 (referent) & $1.24(0.87$ to 1.76$)$ & $1.44(0.87$ to 1.76$)$ & 0.13 \\
\hline Dry cough at night last 12 months & 1 (referent) & $1.27(0.91$ to 1.77$)$ & $1.58(0.93$ to 2.67$)$ & 0.053 \\
\hline Nasal symptoms last 12 months & 1 (referent) & 1.33 (1.03 to 1.72$)$ & $1.39(0.92$ to 2.11$)$ & 0.027 \\
\hline School absence last 12 months & 1 (referent) & $1.38(1.00$ to 1.89$)$ & $2.21(1.34$ to 3.62$)$ & 0.001 \\
\hline Respiratory infections last 12 months & 1 (referent) & $1.03(0.82$ to 1.31$)$ & $1.27(0.86$ to 1.87$)$ & 0.31 \\
\hline Asthma attacks last 12 months & 1 (referent) & $0.91(0.63$ to 1.30$)$ & $1.48(0.83$ to 2.63$)$ & 0.55 \\
\hline
\end{tabular}

not found when extent of damage was considered, except for a slight increase in nasal symptoms with increased extent of dampness observations (see online supplementary table 4). Adding severity of dampness observations to the classification of school buildings indicated a dose-response relationship for wheezing, nocturnal cough and school absence in the last 12 months (see online supplementary table 5). These analyses were also carried out for Spain and the Netherlands but the results were not significant (data not shown).

Finally, we performed several sensitivity analyses. First, we excluded 1450 pupils with any recent moisture damage, dampness or mould in their homes so that the health effects of dampness at home did not mask any potential effect of school dampness in Spain and the Netherlands (where dampness at home was more common than in Finland) (see online supplementary figure 2). In this analysis, respiratory symptoms continued to be more frequent among Finnish pupils in damaged schools compared to non-damaged schools and the point estimates were close to the ORs for all pupils as shown in figure 1. We also limited the analyses to pupils who had attended the school for more than 2 years to focus on long-term exposure. The results pointed in the same direction as the results shown in figure 1 but due to smaller numbers the risk estimates did not reach conventional levels of statistical significance. Finally, we repeated all analysis excluding schools with a response rate below $60 \%$ (see online supplementary figure 3 ) in order to avoid a possible response bias. In this analysis, results for Finnish pupils did not change, but positive and significant associations between moisture damage and nasal symptoms and dry cough at night were seen for Spanish children.

\section{DISCUSSION}

This large European study shows that moisture damage in schools may have adverse respiratory health effects on pupils. Wheezing, nasal symptoms and school absence due to respiratory problems in the last year were significantly associated with dampness at school, in particular when visible mould was present. This association was only apparent among Finnish pupils and there was clear heterogeneity between countries, possibly related to both quantitative and qualitative differences in dampness related exposures in the schools.

Results are consistent with other studies for wheezing and nasal symptoms. ${ }^{1} 272125$ Absence from school, as an indicator of the severity of the underlying respiratory illness, has not been documented in other studies. In addition, most other studies only included one area or one country ${ }^{8} 13$ and in the only international study country-specific results were not presented. ${ }^{21}$ The presence of dry cough at night was associated with moisture at school in a consistent manner for all three countries. This association agrees with the findings of other studies that observed this relationship for dampness at home ${ }^{10}$ or at school $^{8921}$ using quantitative exposure methods.

Simoni et $a l^{21}$ related respiratory health and pulmonary function tests to indoor levels of viable mould and fungal DNA. Levels of viable moulds above $300 \mathrm{cfu} / \mathrm{m}^{3}$ were associated with dry cough at night, rhinitis and persistent cough, while fungal DNA levels were associated with wheeze symptoms, rhinitis and cough, supporting the hypothesis that microbial exposure related to moisture damage in school buildings can cause respiratory health effects in pupils.

The results of the present study are also consistent with previous studies on the effects of dampness in homes, ${ }^{17}$ but differences were observed in relation to some of the outcomes. Having had an asthma attack in the last year was related to dampness at home in our study as well as in other studies, but did not seem to be related to dampness in the school. These apparent inconsistencies between schools and homes may be explained by differences in the duration, quality and quantity of the dampness related exposures.

We did not find the clear associations between moisture damage in the school and respiratory infections found in a meta-analysis regarding home environment. ${ }^{26}$ The reasons for this are not clear. In our study, having moisture damage at home was positively associated with infections with an adjusted country-combined OR of 1.45 (95\% CI 1.26 to 1.66) for recurrent infections in the last year and an adjusted countrycombined OR of 1.21 (95\% CI 1.06 to 1.37 ) for any infection in the last 12 months.

The fact that the associations with school exposure in the present study are only seen in the Nordic country suggests several hypotheses. The first is related to climate. Differences in temperature, latitude or relative humidity $(\mathrm{RH})$ may also be co-exposure factors. For example, lower RH indoors during winter months is expected to be more common in Finnish schools. Indeed, low RH has been observed in a subsample of the schools included in this study in the course of longitudinal follow-up of the HITEA study. Low RH indoors is generally considered harmful and is linked to respiratory irritation, and some European countries have guidelines regarding lower acceptable $\mathrm{RH}$ limits. ${ }^{27}$ In addition, the outdoor and indoor climate may have an impact on microbial exposures in the study schools. The majority of school buildings in Finland (unlike in 
Spain and the Netherlands) have mechanical ventilation systems with natural ventilation via opening windows being rare during an extended heating season. Therefore, the school building microbiome, largely driven by the availability of water and thus linked to dampness in schools, may be very different in Finnish schools compared to the microbiome outdoors in Finland or compared to schools in other countries. However, there is limited information on fungal exposure in relation to climate zone. One study on fungal DNA in hotel rooms found a positive association with low latitude, and a greater proportion of aspergillus/penicillium in higher than lower latitudes. ${ }^{28}$

Another possible hypothesis relates to differences in the characteristics of dampness and moisture damage observations in schools in the three countries ${ }^{22}$ and to differences in building types and building materials used. In Finland, mould odour, an indicator of hidden damage in the construction of the building, ${ }^{4}$ was more frequent $(17 \%)$ than in the other two countries $(4 \%$ in Spain and 7\% in the Netherlands). ${ }^{22}$ Some authors have indicated that mould odour is a good predictor of the presence of active microbial growth. ${ }^{29}$ Others have found that the type of building frame can be a determinant of exposure and also of symptoms. ${ }^{8}$ There might be more moisture in the construction materials of buildings in Finland, for instance due to excessive moisture and insufficient drying during construction or due to moisture accumulation during use. Such building frame problems may give rise to 'hidden' microbial proliferation that might explain the difference in the health effects observed.

Another possible explanation for the observations specific to Finland is that the effects are present in all three countries but are not observed in Spain and the Netherlands due to a bias relating to the lower response rates in damaged schools in these two countries. This hypothesis was explored in the sensitivity analysis which included only schools with a higher response rate $(>60 \%)$. For Spain, at least some of the outcomes (dry cough at night and nasal symptoms) shifted towards a positive association. However, this effect was not seen in schools from the Netherlands.

People in Finland are very aware of the dampness issue and its effect on health, which could have led to a reporting bias. However, other symptoms typically not linked with dampness in buildings, such as hay fever, were also significantly more likely in damaged schools in Finland compared to the other two countries.

We investigated in a sensitivity analyses whether a higher prevalence of dampness and mould at home in Spain and the Netherlands could mask the effect of dampness in the damaged schools in these two countries. However, the tendencies we found in the sensitivity analysis were similar to the observations in the overall dataset, suggesting that the lack of association between respiratory symptoms and moisture at school in Spain and the Netherlands is not due to the influence of home exposure (see online supplementary figure 2 ).

The relatively low response rate in particular in damaged schools in Spain and the Netherlands was one of the limitations of this study. Nevertheless, the frequencies of health symptoms in the last year reported by our study population (table 2) are similar to those in other epidemiological studies, ${ }^{30}$ which indicates that the studied children were representative of the overall population.

Another study limitation is related to the exposure assessment. In our analysis, the school exposure is assumed to be the same for all pupils in the same school building. To improve the exposure assessment, the present study used a semi-quantitative method to assess the extent and location of damage. We are aware that using this type of method to assess exposure has limitations and has been criticised by other authors, ${ }^{21}$ but other investigators have defended the use of these methods compared to a quantitative approach. ${ }^{1} 731$

The cross-sectional design of this study could lead to the problem of reverse causation and selection bias due to avoidance of damaged schools by (the parents of) children with respiratory conditions. We consider this bias to be unlikely or to only occur for severe asthma cases. Prospective studies in homes have found that exposure to indoor moisture and dampness during early life is associated with an increased risk of respiratory problems (asthma symptoms such as wheezing and allergic rhinitis symptoms) in later life. ${ }^{11} 32$ Some prospective studies in schools have been carried out in Asia, but they did not investigate moisture as their principal exposure. ${ }^{33} 34$ To confirm the presence of this type of bias, prospective studies should be undertaken in schools.

One of the strengths of this study is the large number of observations from different countries carried out under the same protocol. Moreover, the use of a semi-quantitative method (including reports and observations) to assess moisture exposure in schools is an advantage as more exposures will be included than with strictly quantitative approaches. We also considered a large number of possible confounders and adjusted for these to avoid any possible residual confounding.

In conclusion, this large European study shows that moisture damage in schools may have adverse respiratory health effects on pupils. Considering the prevalence of such problems, moisture damage and dampness in schools need to be regarded as a serious public health issue and remediation of damaged schools should carried out in order to provide healthy indoor environments for pupils and teachers. ${ }^{9} 1335$ In particular, Finnish schoolchildren seem to be at higher risk, possibly due to both quantitative and qualitative differences in exposure characteristics. Differences in adverse health outcomes due to exposure to dampness and mould between countries and the characteristics of microbial exposures linked to dampness in the schools will be further explored in follow-up surveys of the HITEA study.

Funding This study was financially supported by the European Commission as part of HITEA (Health Effects of Indoor Pollutants: Integrating Microbial, Toxicological and Epidemiological Approaches), Grant agreement no. 211488 under the Seventh Framework Programme, Topic ENV.2007.1.2.1.1. 'Indoor air pollution in Europe: An emerging environmental health issue' and Juho Vainion Säätiö. The first author received an ERS and SEPAR short-term research fellowship to work on this paper.

\section{Competing interests None.}

Ethics approval This study was conducted with the approval of the ethics committees of the three local research institutes.

Provenance and peer review Not commissioned; externally peer reviewed.

\section{REFERENCES}

1 World Health Organization (WHO) Regional Office for Europe. Guidelines for indoor air quality: dampness and mould. Copenhagen, Denmark: WHO Regional Office for Europe, 2009.

2 Institute of Medicine. Damp indoor spaces and health. Washington, DC: National Academies Press, 2004.

3 Haverinen-Shaughnessy U. Prevalence of dampness and mold in European housing stock. J Expo Sci Environ Epidemiol 2012;22:461-7.

4 Bornehag CG, Blomquist G, Gyntelberg $F$, et al. Dampness in buildings and health. Nordic interdisciplinary review of the scientific evidence on associations between exposure to "dampness" in buildings and health effects (NORDDAMP). Indoor Air 2001;11:72-86

5 Bornehag CG, Sundell J, Bonini S, et al. EUROEXPO. Dampness in buildings as a risk factor for health effects, EUROEXPO: a multidisciplinary review of the literature (1998-2000) on dampness and mite exposure in buildings and health effects. Indoor Air 2004;14:243-57.

6 Fisk WJ, Lei-Gomez Q, Mendell MJ. Meta-analyses of the associations of respiratory health effects with dampness and mold in homes. Indoor Air 2007:17:284-96. 
7 Mendell MJ, Mirer AG, Cheung K, et al. Respiratory and allergic health effects of dampness, mold, and dampness-related agents: a review of the epidemiologic evidence. Environ Health Perspect 2011;119:748-56.

8 Meklin T, Husman T, Vepsalainen A, et al. Indoor air microbes and respiratory symptoms of children in moisture damaged and reference schools. Indoor Air 2002;12:175-83.

9 Meklin T, Potus T, Pekkanen J, et al. Effects of moisture-damage repairs on microbial exposure and symptoms in schoolchildren. Indoor Air 2005;15(Suppl 10):40-7.

10 Antova T, Pattenden S, Brunekreef B, et al. Exposure to indoor mould and children's respiratory health in the PATY study. J Epidemiol Comm Health 2008;62:708-14.

11 Tischer C, Gehring U, Chen CM, et al. Respiratory health in children, and indoor exposure to (1,3)-beta-D-glucan, EPS mould components and endotoxin. Eur Respir J 2011;37:1050-9.

12 Meyer HW, Würtz $\mathrm{H}$, Suadicani $\mathrm{P}$, et al. Molds in floor dust and building-related symptoms in adolescent school children. Indoor Air 2004;14:65-72.

13 Haverinen-Shaughnessy U, Pekkanen J, Nevalainen A, et al. Estimating effects of moisture damage repairs on students' health-a long-term intervention study. J Exp Anal Environ Epidemiol 2004;14(Suppl 1):58-64.

14 Smedje G, Norbäck D, Edling C. Asthma among secondary schoolchildren in relation to the school environment. Clin Exp Allergy 1997;27:1270-8.

15 Rylander R, Norrhall M, Engdahl U, et al. Airways inflammation, atopy, and (1-> 3)-beta-D-glucan exposures in two schools. Am J Respir Crit Care Med 1998;158:1685-7.

16 Savilahti R, Uitti J, Laippala P, et al. Respiratory morbidity among children following renovation of a water-damaged school. Arch Environ Health 2000;55:405-10.

17 Savilahti R, Uitti J, Roto $P$, et al. Increased prevalence of atopy among children exposed to mold in a school building. Allergy 2001;56:175-9.

18 Mi YH, Norbäck D, Tao J, et al. Current asthma and respiratory symptoms among pupils in Shanghai, China: influence of building ventilation, nitrogen dioxide, ozone, and formaldehyde in classrooms. Indoor Air 2006;16:454-64.

19 Cai GH, Hashim JH, Hashim Z, et al. Fungal DNA, allergens, mycotoxins and associations with asthmatic symptoms among pupils in schools from Johor Bahru, Malaysia. Pediatr Allergy Immunol 2011;22:290-7.

20 Zhao Z, Sebastian A, Larsson L, et al. Asthmatic symptoms among pupils in relation to microbial dust exposure in schools in Taiyuan, China. Pediatr Allergy Immunol 2008; 19:455-65.

21 Simoni M, Cai GH, Norback D, et al. Total viable molds and fungal DNA in classrooms and association with respiratory health and pulmonary function of European schoolchildren. Pediatr Allergy Immunol 2011;22:843-52.
22 Haverinen-Shaughnessy U, Borras-Santos A, Turunen M, et al. Occurrence of moisture problems in schools in three countries from different climatic regions of Europe based on questionnaires and building inspections-the HITEA study. Indoor Air 2012 Dec;22(6):457-66.

23 Asher MI, Keil U, Anderson HR, et al. International Study of Asthma and Allergies in Childhood (ISAAC): rationale and methods. Eur Respir J 1995;8:483-91.

24 Hedges LV, Vevea JL. Fixed- and random-effects models in meta-analysis. Psychol Meth 1998:3:486-504.

25 Tham KW, Zuraimi MS, Koh D, et al. Associations between home dampness and presence of molds with asthma and allergic symptoms among young children in the tropics. Pediatr Allergy Immunol 2007;18:418-24.

26 Fisk WJ, Eliseeva EA, Mendell MJ. Association of residential dampness and mold with respiratory tract infections and bronchitis: a meta-analysis. Environ Health. 2010;9:72.

27 Arundel AV, Sterling EM, Biggin JH, et al. Indirect health effects of relative humidity in indoor environments. Environ Health Perspect 1986;65:351-61.

28 Norbäck D, Cai GH. Fungal DNA in hotel rooms in Europe and Asia-associations with latitude, precipitation, building data, room characteristics and hotel ranking. J Environ Monit 2011;13:2895-903.

29 Jones $\mathrm{R}$, Recer GM, Hwang SA, et al. Association between indoor mold and asthma among children in Buffalo, New York. Indoor Air 2011;21:156-64.

30 Simoni M, Annesi-Maesano I, Sigsgaard T, et al. School air quality related to dry cough, rhinitis and nasal patency in children. Eur Respir J 2010;35:742-9.

31 Holme J, Hägerhed-Engman L, Mattsson J, et al. Culturable mold in indoor air and its association with moisture-related problems and asthma and allergy among Swedish children. Indoor Air 2010;20:329-40.

32 Karvonen AM, Hyvärinen A, Roponen $\mathrm{M}$, et al. Confirmed moisture damage at home, respiratory symptoms and atopy in early life: a birth-cohort study. Pediatrics 2009;124:e329-38.

33 Zhang $X$, Zhao Z, Nordquist $T$, et al. A longitudinal study of sick building syndrome among pupils in relation to microbial components in dust in schools in China. Sci Total Environ 2011:409:5253-9.

34 Smedje G, Norbäck D. Incidence of asthma diagnosis and self-reported allergy in relation to the school environment-a four-year follow-up study in schoolchildren. Int J Tuberc Lung Dis 2001;5:1059-66.

35 Krieger J, Jacobs DE, Ashley PJ, et al. Housing interventions and control of asthma-related indoor biologic agents: a review of the evidence. J Public Health Manag Pract 2010;16(5 Suppl):S11-20. 